\title{
Clinical Effectiveness of High-Flow Nasal Cannula in Hypoxaemic Patients during Bronchoscopic Procedures
}

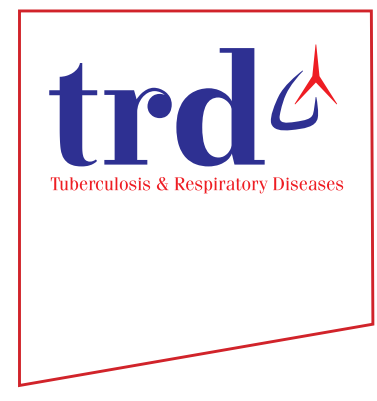

\author{
Sang Mi Chung, M.D. ${ }^{\circledR}$, Ju Whan Choi, M.D., Young Seok Lee, M.D., Ph.D., Jong Hyun Choi, M.D., \\ Jee Youn Oh, M.D., Ph.D., Kyung Hoon Min, M.D., Ph.D., Gyu Young Hur, M.D., Ph.D., Sung Yong \\ Lee, M.D., Ph.D. ${ }^{\mathbb{D}}$, Jae Jeong Shim, M.D., Ph.D. and Kyung Ho Kang, M.D., Ph.D. \\ Division of Respiratory and Critical Care Medicine, Korea University Guro Hospital, Seoul, Korea
}

Background: Bronchoscopy is a useful diagnostic and therapeutic tool. However, the clinical use of high-flow nasal cannula (HFNC) in adults with acute respiratory failure for diagnostic and invasive procedures has not been well evaluated. We present our experiences of well-tolerated diagnostic bronchoscopy as well as cases of improved saturation in hypoxaemic patients after a therapeutic bronchoscopic procedure.

Methods: We retrospectively reviewed data of hypoxaemic patients who had undergone bronchoscopy for diagnostic or therapeutic purposes from October 2015 to February 2017.

Results: Ten patients (44-75 years of age) were enrolled. The clinical purposes of bronchoscopy were for diagnosis in seven patients and for intervention in three patients. For the diagnoses, we performed bronchoalveolar lavage in six patients. One patient underwent endobronchial ultrasonography with transbronchial needle aspiration of a lymph node to investigate tumour involvement. Patients who underwent bronchoscopy for therapeutic interventions had endobronchial mass or blood clot removal with cryotherapy for bleeding control. The mean saturation $\left(\mathrm{SpO}_{2}\right)$ of prebronchoscopy in room air was $\mathbf{8 4 . 1 \%}$. The lowest and highest mean saturation with HFNC during the procedure was $95 \%$ and 99.4 , respectively. The mean saturation in room air post-bronchoscopy was $87.4 \%$, which was $3.3 \%$ higher than the mean room air $\mathrm{SpO}_{2}$ pre-bronchoscopy. Seven patients with diagnostic bronchoscopy had no hypoxic event. Three patients with interventional bronchoscopy showed improvement in saturation after the procedure. Bronchoscopy was well tolerated in all 10 cases.

Conclusion: This study suggests that the use of HFNC in hypoxaemic patients during diagnostic and therapeutic bronchoscopy procedures has clinical effectiveness.

Keywords: Bronchoscopy; Cannula; Hypoxia; Oxygen; Hypoxemia

Address for correspondence: Sung Yong Lee, M.D., Ph.D.

Division of Respiratory and Critical Care Medicine, Korea University Guro Hospital, 148 Gurodong-ro, Guro-gu, Seoul 08308, Korea

Phone: 82-2-2626-3030, Fax: 82-2-2626-1166

E-mail: pusarang@gmail.com

Received: Sep. 11, 2017

Revised: Dec. 8, 2017

Accepted: Mar. 5, 2018

Published online: Jun. 19, 2018

(c) It is identical to the Creative Commons Attribution Non-Commercial License (http://creativecommons.org/licenses/by-nc/4.0/).

\section{Introduction}

Acute respiratory failure (ARF) has long been a challenge for physicians who perform bronchoscopy for diagnostic or therapeutic purposes. Hypoxaemia is aggravated when implementing bronchoalveolar lavage (BAL) or therapeutic intervention. Many physicians lose their chance to perform bronchoscopy and acquire adequate samples for appropriate treatment. Since undergoing a bronchoscopy can be hazardous to patients with ARF, intubation is preferred and physicians are reluctant to achieve BAL sample. Therefore, bronchoscopic procedures in high-risk patients, especially those with hypoxaemia, have long been a challenge in this field. 
Conventional oxygen therapy (low flow $\mathrm{O}_{2}$ system, noninvasive ventilation [NIV]) was known to improve the outcome of hypoxaemic patients. Comparing with high flow nasal cannula (HFNC) group, there were no significant differences in the reintubation rate or length of intensive care unit stay in a meta-analysis study ${ }^{1}$.

HFNC therapy provides accurate oxygen delivery, wash out of anatomical dead space, and a low-level of positive pressure $^{2}$. The devices deliver heated and humidified oxygen at a maximum flow rate of up to $60 \mathrm{~L} / \mathrm{min}$ via nasal cannula, and enable the maintenance of the fraction of oxygen above $95 \%^{3,4}$.

Miyagi et al. ${ }^{2}$ presented five cases that underwent BAL with the use of HFNC; the patients tolerated the procedure despite hypoxia and dyspnoea. However, the shortage of cases could not confirm the clinical efficacy and safety of HFNC use during bronchoscopy and BAL. Simon et al. ${ }^{5}$ reported that NIV was superior to HFNC with regard to oxygenation before, during, and after bronchoscopy in patients with moderate to severe hypoxaemia. However, patients who were stable on HFNC tolerated the bronchoscopy well ${ }^{5}$.

Few clinical studies have shown the effectiveness of performing bronchoscopy using HFNC in ARF for diagnostic purpose. Moreover, there is no clinical practice that improves oxygenation after performing therapeutic intervention with bronchoscopy. Therefore, we conducted a retrospective study to clarify the clinical effectiveness of high-flow nasal cannula in hypoxaemic patients during a diagnostic and interventional bronchoscopy.

\section{Materials and Methods}

This is a retrospective, observational, single center study approved by the ethics committee of the Korea University Guro Hospital. Informed consent was waived due to the retrospective study.

All patients were selected by the Pulmonology Department at a single academic hospital to undergo fiberoptic bronchoscopy and BAL fluid collection for diagnostic purposes or mass removal and cryotheraputic intervention for therapeutic purposes. Patients who had a peripheral arterial pulse oximetry value $\left(\mathrm{SpO}_{2}\right)$ less than $90 \%$ in room air setting were included in this study. Subjects with tracheostomy, requiring home oxygen therapy or mechanical or noninvasive ventilation, nasal or nasopharyngeal disease, not able to clearly express themselves, and pregnant individuals were excluded from the study.

The procedures for all 10 patients were conducted in the same environment. The patients were in the supine position and we administered a mixture of humidified gas warmed by a servo-controlled heated respiratory humidifier (MR730; Fisher \& Paykel, Auckland, New Zealand). Baseline room air peripheral saturation $\left(\mathrm{SpO}_{2}\right)$, heart rate, and respiratory rate were measured before the procedure during spontaneous breathing on room air.

For local anaesthesia, $2 \%$ nebulized lidocaine was sprayed twice through the mouth and nostrils. For all patients, a resting period of approximately 5 minutes was needed for the local anaesthesia to fully take effect. Conscious sedation was achieved with midazolam and propofol, which were administered intravenously at maximum doses of $0.1 \mathrm{mg} / \mathrm{kg}$ body weight. Fibreoptic bronchoscopy (18-F; Olympus, Corp, Tokyo, Japan) was initiated through a nostril. HFNC was applied through both nostrils. BAL was performed by instilling and aspirating 100 to $150 \mathrm{ml}$ of a saline solution $(\mathrm{NaCl} 0.9 \%)$ ample fluid. The highest and lowest saturation $\left(\mathrm{SpO}_{2}\right)$, heart rate, and respiratory rate were checked during the procedure. The total duration of the bronchoscopy was measured for each patient. At the end of the procedure, the post-bronchoscopy saturation $\left(\mathrm{SpO}_{2}\right)$ was checked while applying HFNC and on room air after 5 minutes.

\section{Results}

\section{Patient characteristics}

The demographic and clinical characteristics are depicted in Table 1. A total of 10 patients ( 3 females and 7 males), ranging from 44 to 75 years of age were enrolled. The clinical reasons for bronchoscopy were diagnostic in seven patients and interventional in three patients. Each patient had more than one comorbidity including pneumonia, chronic obstructive pulmonary disease, interstitial lung disease, and lung cancer. Three patients did not have pulmonary function test records,

Table 1. Demographic and clinical characteristics of subjects in the study

\begin{tabular}{|ll|}
\hline \multicolumn{1}{|c|}{ Characteristic } & No. $(\mathbf{n}=\mathbf{1 0})$ \\
\hline Male sex, n (\%) & $7(70)$ \\
Age, median (range), yr & $67.3(44-75)$ \\
Smoking & 3 (33 pack-years) \\
Current smoking & 1 (90 pack-years) \\
Ex-smoker & 6 \\
Never smoker & \\
Reasons for acute respiratory failure & 5 \\
Pneumonia & 5 \\
Lung cancer & 3 \\
COPD & 3 \\
Interstitial lung disease & $7: 3$ \\
Diagnostic purpose:Therapeutic purpose & \\
\hline
\end{tabular}

COPD: chronic obstructive pulmonary disease. 
while five patients had a forced expiratory volume in the first second more than $1.0 \mathrm{~L}$ and the diffusing capacity of the lungs for carbon monoxide varied between $34 \%$ and $60 \%$.

\section{Clinical status during bronchoscopic procedures}

Seven patients were sedated during bronchoscopy, with close monitoring of heart rate, $\mathrm{SpO}_{2}$, electrocardiogram, and respiratory rate. Baseline room air peripheral saturation $\left(\mathrm{SpO}_{2}\right)$, heart rate, and respiratory rate were measured before the procedure during spontaneous breathing in room air.

For diagnostic purposes, we performed BAL in five patients with acute pneumonia and one patient with lung cancer. One patient underwent an endobronchial ultrasound transbronchial needle aspiration of a lymph node to evaluate for cancer metastasis. Patients who underwent therapeutic intervention did so for an endobronchial mass or blood clot removal with cryotherapy for bleeding control.

The clinical statuses of the 10 cases that underwent a bronchoscopic procedure with HFNC are shown in Table 2 and vital status before and after bronchoscopy in Table 3. All patients were hypoxic at baseline; therefore, we used HFNC with different settings for each patient. In Figure 1, we compared the $\mathrm{SpO}_{2} /$ fraction of inspired oxygen $\left(\mathrm{FiO}_{2}\right)$ ratio (S/F ratio) prebronchoscopy and postbronchoscopy. Most of the patients undergoing bronchoscopy for diagnosis well tolerated during the procedure by applying HFNC. Three patients undergoing bronchoscopy for therapeutic intervention showed substantial improvement of oxygenation after bronchoscopy on room air after 5 minutes. The mean S/F ratio increase was 35.3.

\section{Safety}

We were able to discontinue HFNC in all patients after the diagnostic or interventional bronchoscopy were performed. No patient required noninvasive positive pressure ventilation or mechanical ventilation after the completion of the bronchoscopy. HFNC was well tolerated in all 10 cases.

\section{Discussion}

Our study was the first to introduce the clinical effectiveness of HFNC for diagnostic and therapeutic interventional bronchoscopy and clarify its usefulness and safety in acute hypoxaemia. HFNC can deliver oxygen at high flow rates (40-60 L/min), permitting a high $\mathrm{FiO}_{2}$. Mucosal injury and patient discomfort is prevented by humidified and heated gas ${ }^{6}$. Current common clinical applications are to reduce the risk of intubation in patients with moderate or severe hypoxaemia $\left(\mathrm{PaO}_{2}: \mathrm{FiO}_{2}<200 \mathrm{~mm} \mathrm{Hg}\right)^{7}$.

The patients in our study can be divided into two groups; one is the diagnostic intervention group and the other the

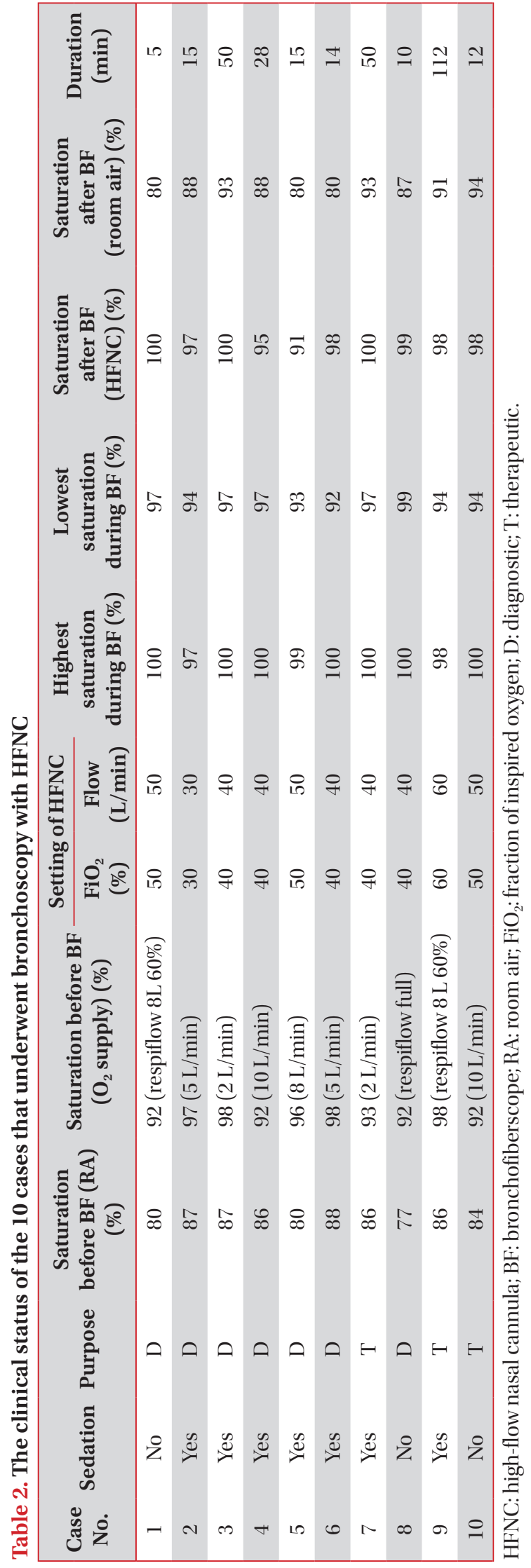


Table 3. Clinical information of 10 patients before and after bronchoscopic procedures

\begin{tabular}{|c|c|c|c|c|c|c|}
\hline \multirow{2}{*}{ Case No. } & \multicolumn{3}{|c|}{ Before bronchoscopy } & \multicolumn{3}{|c|}{ After bronchoscopy } \\
\hline & HR (/min) & $\mathrm{RR}(/ \mathrm{min})$ & $\mathrm{BP}(\mathrm{mm} \mathrm{Hg})$ & $\mathrm{HR}(/ \mathrm{min})$ & $\mathrm{RR}(/ \mathrm{min})$ & $\mathrm{BP}(\mathrm{mm} \mathrm{Hg})$ \\
\hline 1 & 113 & 30 & $114 / 75$ & 100 & 30 & $95 / 63$ \\
\hline 2 & 70 & 25 & $140 / 70$ & 132 & 35 & $140 / 70$ \\
\hline 3 & 120 & 25 & $110 / 70$ & 125 & 25 & $140 / 80$ \\
\hline 4 & 88 & 34 & $160 / 80$ & 100 & 25 & $132 / 75$ \\
\hline 5 & 130 & 36 & $120 / 80$ & 123 & 33 & $130 / 90$ \\
\hline 6 & 122 & 22 & $109 / 83$ & 115 & 26 & $120 / 90$ \\
\hline 7 & 80 & 28 & $110 / 70$ & 123 & 39 & $110 / 60$ \\
\hline 8 & 106 & 20 & $110 / 70$ & 105 & 20 & $100 / 70$ \\
\hline 9 & 85 & 22 & $110 / 70$ & 102 & 21 & $100 / 64$ \\
\hline 10 & 109 & 24 & $134 / 60$ & 107 & 24 & $130 / 80$ \\
\hline
\end{tabular}

HR: heart rate; RR: respiration rate; BP: blood pressure.

A

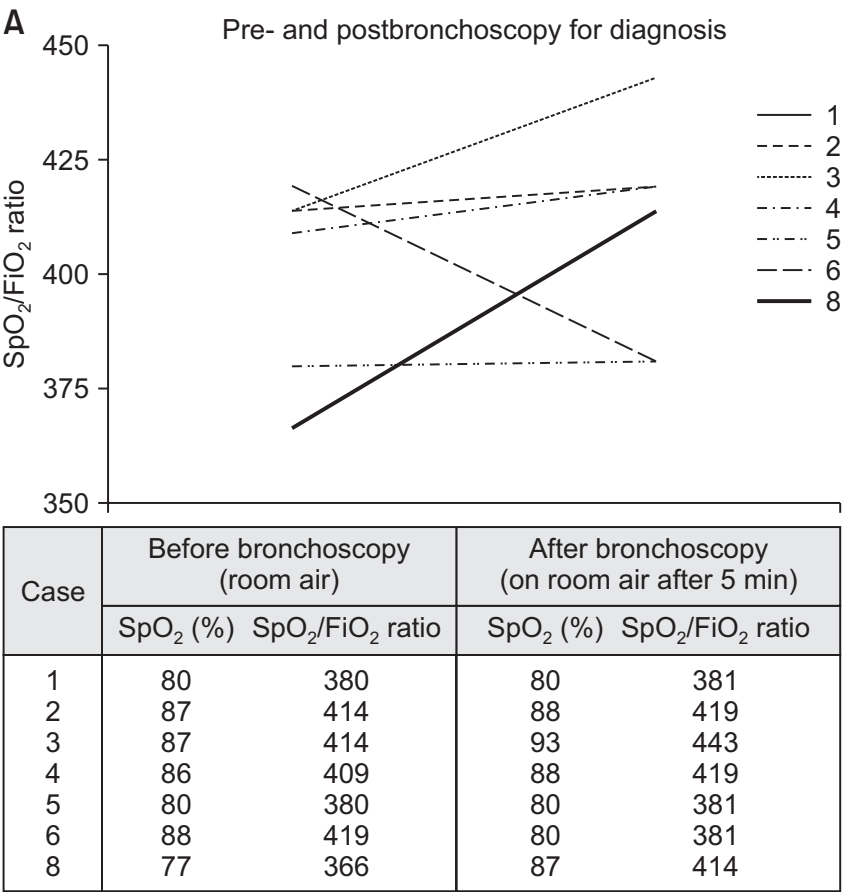

B $450 \quad$ Pre- and postbronchoscopy for intervention

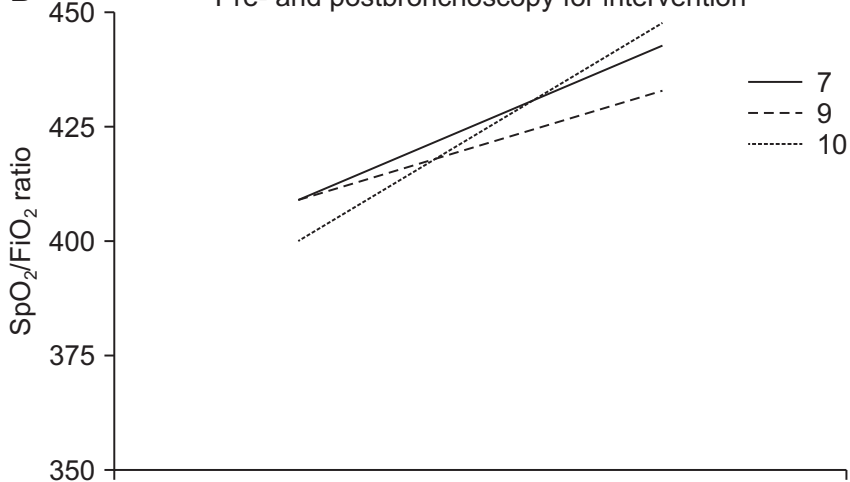

Figure 1. (A) Prebronchoscopy and postbronchoscopy saturation and $\mathrm{SpO}_{2} / \mathrm{FiO}_{2}$ ratio in diagnostic bronchoscopy. (B) Prebronchoscopy and postbronchoscopy saturation and $\mathrm{SpO}_{2} / \mathrm{FiO}_{2}$ ratio in therapeutic intervention. $\mathrm{SpO}_{2}$ : peripheral arterial pulse oximetry; FiO ${ }_{2}$ fraction of inspired oxygen.

therapeutic intervention group. Among seven patients who had undergone surveillance bronchoalveolar lavage, two patients were found to be influenza A positive by a respiratory virus polymerase chain reaction test. Despite the low yield from bronchoalveolar lavage, the use of HFNC can reduce dyspnoea and discomfort during the procedure, as well as the rate of intubation and duration of hospital stay of the patient during an infection, which can further improve the outcome.
HFNC was applied to both nostrils and the flow in the nostril where the bronchoscope is inserted could have been influenced by the narrowing of the lumen. However, pre and post bronchoscopy $\mathrm{SpO}_{2}$ had no difference.

Lucangelo et al. ${ }^{8}$ presented a clinical study that determined the effects of HFNC on gas exchange and cardiovascular variables in patients undergoing bronchoscopy and BAL. The included patients had a $\mathrm{SpO}_{2} \geq 90 \%$ and a body mass index 
ranging from 21 to $30^{8,9}$. In Lucangelo et al's study ${ }^{8}, 15$ patients were applied $60 \mathrm{~L} / \mathrm{min}$ HFNC during bronchoscopy; however, his study has limitations since it was conducted in patients with mild respiratory dysfunction. Our study has an impact because we showed the efficacy in real clinical scenarios with severe hypoxaemia $\left(\mathrm{SpO}_{2}<90 \%\right)$. All patients maintained $\mathrm{SpO}_{2}>91 \%$ and no complications were found during and after the procedure. The $\mathrm{SpO}_{2}$ change after the therapeutic intervention, the airway obstruction was solved and resulted in improved room air saturation in three patients (Nos. 7, 9, and 10) (Figure 1).

We carefully suggest an indication for HFNC during bronchoscopy. In an acute infection, where BAL is useful for diagnostic purposes and specimen collection, the use of HFNC during bronchoscopy could be appropriate. An added benefit is the humidified and heated air which can prevent thick secretions and atelectasis. In addition, it is well known that HFNC generates a low level of positive end-expiratory pressure and decreases the dead space of the airway ${ }^{3,9}$. However HFNC should not be applied when there is chronic lung disease. Another suggested indication is interventional bronchoscopy in an acutely hypoxaemic state, such as during tumour removal in patients with dyspnoea. Avoiding endotracheal intubation and reducing the need for general anaesthesia in these patients were mentioned as a promising element in case reports and other articles ${ }^{10}$. All patients were admitted to the general ward rather than the intensive care unit.

There were two limitations to our study. First, the sample size was small. We conducted our investigation at a single center. A multicenter study is required and should be conducted in the near future. Second, since our study was performed retrospectively, setting control group was difficult. Therefore, a prospective case-control study should be conducted in order to determine the clinical indications for diagnostic and therapeutic interventions. In the prospective study, $\mathrm{PaO}_{2}, \mathrm{pCO}_{2}$, $\mathrm{SpO}_{2}$, and $\mathrm{pH}$ before and after bronchoscopy should all be investigated to clarify the role of HFNC in hypercapnic and hypoxaemic patients.

However, our study has clinical significance in suggesting HFNC indication for hypoxaemic patients before starting the bronchoscopy and to safely finish the procedure. All 10 patients undergone procedures had successful diagnosis and improvement in hypoxaemia. This study can serve as a good background for the prospective case-control study in the near future.

\section{Authors' Contributions}

Conceptualization: Chung SM, Lee SY. Formal analysis:
Chung SM, Choi JW. Data curation: Chung SM, Lee SY. Software: Oh JY, Hur GY. Administrative support and study supervision: Min KH, Shim JJ, Kang KH. Writing - original draft preparation: Chung SM, Choi JH. Writing - review and editing: Chung SM, Lee YS. Final approval of manuscript: all authors.

\section{Conflicts of Interest}

No potential conflict of interest relevant to this article was reported.

\section{References}

1. Zhu Y, Yin H, Zhang R, Wei J. High-flow nasal cannula oxygen therapy vs conventional oxygen therapy in cardiac surgical patients: a meta-analysis. J Crit Care 2017;38:123-8.

2. Miyagi K, Haranaga S, Higa F, Tateyama M, Fujita J. Implementation of bronchoalveolar lavage using a high-flow nasal cannula in five cases of acute respiratory failure. Respir Investig 2014;52:310-4.

3. Cuquemelle E, Pham T, Papon JF, Louis B, Danin PE, Brochard L. Heated and humidified high-flow oxygen therapy reduces discomfort during hypoxemic respiratory failure. Respir Care 2012;57:1571-7.

4. Nishimura M. High-flow nasal cannula oxygen therapy in adults. J Intensive Care 2015;3:15.

5. Simon M, Braune S, Frings D, Wiontzek AK, Klose H, Kluge S. High-flow nasal cannula oxygen versus non-invasive ventilation in patients with acute hypoxaemic respiratory failure undergoing flexible bronchoscopy: a prospective randomised trial. Crit Care 2014;18:712.

6. Goligher EC, Slutsky AS. Not just oxygen? Mechanisms of benefit from high-flow nasal cannula in hypoxemic respiratory failure. Am J Respir Crit Care Med 2017;195:1128-31.

7. Frat JP, Thille AW, Mercat A, Girault C, Ragot S, Perbet S, et al. High-flow oxygen through nasal cannula in acute hypoxemic respiratory failure. N Engl J Med 2015;372:2185-96.

8. Lucangelo U, Vassallo FG, Marras E, Ferluga M, Beziza E, Comuzzi L, et al. High-flow nasal interface improves oxygenation in patients undergoing bronchoscopy. Crit Care Res Pract 2012;2012:506382.

9. Sztrymf B, Messika J, Bertrand F, Hurel D, Leon R, Dreyfuss D, et al. Beneficial effects of humidified high flow nasal oxygen in critical care patients: a prospective pilot study. Intensive Care Med 2011;37:1780-6.

10. Diab S, Fraser JF. Maintaining oxygenation successfully with high flow nasal cannula during diagnostic bronchoscopy on a postoperative lung transplant patient in the intensive care. Case Rep Crit Care 2014;2014:198262. 